\title{
An Investigation on Cocombustion Behaviors of Hydrothermally Treated Municipal Solid Waste with Coal Using a Drop-Tube Reactor
}

\author{
Liang Lu, ${ }^{1}$ Yuqi Jin, ${ }^{2}$ Masato R. Nakamura, ${ }^{3}$ Marco J. Castaldi, ${ }^{3}$ and Kunio Yoshikawa ${ }^{1}$ \\ ${ }^{1}$ Department of Environmental Science and Technology, Tokyo Institute of Technology, Yokohama 226-8503, Japan \\ ${ }^{2}$ State Key Laboratory of Clean Energy Utilization, Institute for Thermal Power Engineering, Zhejiang University, Hangzhou, China \\ ${ }^{3}$ Earth Engineering Center and Department of Earth and Environmental Engineering, Columbia University, New York, NY, USA
}

Correspondence should be addressed to Liang Lu, lu.l.ae@m.titech.ac.jp

Received 15 June 2012; Accepted 2 August 2012

Academic Editor: Constantine D. Rakopoulos

Copyright () 2012 Liang Lu et al. This is an open access article distributed under the Creative Commons Attribution License, which permits unrestricted use, distribution, and reproduction in any medium, provided the original work is properly cited.

\begin{abstract}
This work aims at demonstrating the feasibility of replacing Indonesian coal (INC) with hydrothermally treated municipal solid waste (MSWH) in cocombustion with high ash Indian coal (IC). The combustion efficiencies and emissions (CO, NO) of MSWH, INC and their blends with IC for a series of tests performed under a range of temperatures and air conditions were tested in a droptube reactor (DTR). The results showed the following. The combustion efficiency of IC was increased by blending both MSWH and INC and $\mathrm{CO}$ emission was reduced with increasing temperature. For NO emission, the blending of MSWH led to the increase of NO concentration whereas the effects of INC depended on the temperature. The combustion behaviors of IC-MSWH blend were comparable to those of the IC-INC blend indicating it is possible for MSWH to become a good substitute for INC supporting IC combustion. Moreover, the CO emission fell while the NO emission rose with increasing excess air for IC-MSWH blend at $900^{\circ} \mathrm{C}$ and the highest combustion efficiency was obtained at the excess air of 1.9. The existence of moisture in the cocombustion system of IC-MSWH blend could slightly improve the combustion efficiency, reduce CO, and increase NO.
\end{abstract}

\section{Introduction}

With the development of human civilization, municipal solid waste (MSW) turns out to be a great threat to the environment. Traditional MSW disposal methods such as open dumping, landfill, or composting are becoming less and less attractive due to less land available around cities and also much more stringent environmental regulations. Thermal treatment as incineration will therefore play an important role as an effective MSW treatment which enjoys the advantages of outstanding reduction in waste volume, thermal destruction of toxic organic constituents, and so forth. However, it is hard to recycle adequate energy from the incineration of MSW with high moisture content, heterogeneous characteristics, and low energy content. Recently, hydrothermal treatment (HT) is regarded to be an effective waste to energy technology for converting MSW into solid fuels with low moisture content, uniform characteristics, and high bulk/energy density [1-5].

On the other hand, we are running out of high-rank coals for power generations so that the utilizations of lowrank coals are inevitable especially in developing countries. For example, Indian coal (IC) is one kind of coal with high ash content which leads to difficulty in ignition and maintenance of flame stabilization, and so forth. In reality, Indonesian coal (INC) is blended with IC in power plants in India in order to alleviate the adverse impact induced by IC. Nevertheless, there are still a lot of problems related to the utilization of INC as an additive: uncertainty in availability and price, higher energy content compared to IC, and so forth. In our previous work, experiments were carried out with thermogravimetric analysis (TGA) and the results proved that hydrothermally treated MSW (MSWH) has the capability to promote the combustion of low-quality IC and 


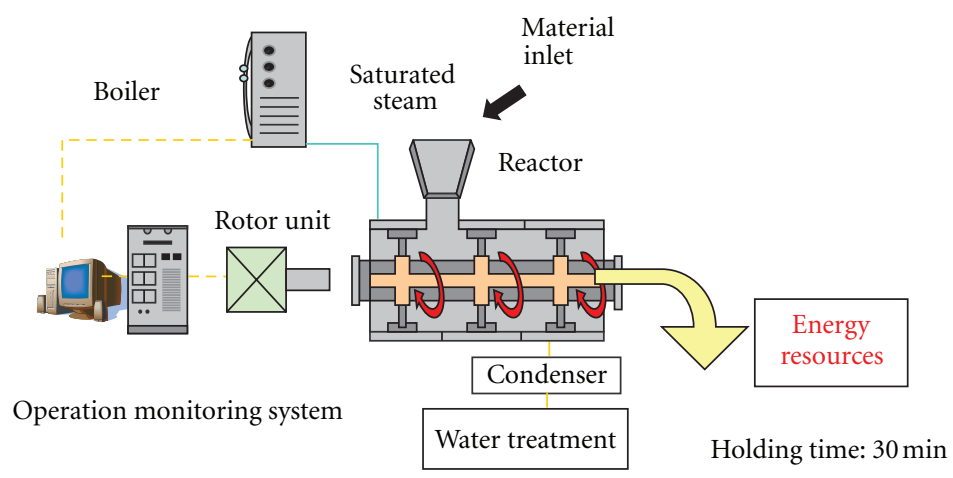

Figure 1: Hydrothermal treatment system.

is competitive compared to INC especially in terms of the enhancements in ignition and burnout behaviors $[1,3,4]$. However, little has been clarified with respect to combustion efficiencies and emissions in real combustors.

In this work, a drop tube reactor (DTR) is utilized to have a closer simulation of the real pulverized coal combustion system than TGA $[6,7]$. The temperatures used in this study are $800,900,1000$, and $1100^{\circ} \mathrm{C}$ in order to find out the influence of temperature on combustion behaviors. Individual IC, MSWH, INC and their blends at 80\% IC: $20 \%$ MSWH and 90\% IC: $10 \%$ INC (wt \%) are tested in the DTR to evaluate the effectiveness of the blends in the combustion enhancement compared to IC only and the feasibility of the replacement of INC with MSWH in terms of combustion efficiency and emissions.

\section{Experimental}

2.1. Material Sources. The two kinds of testing coal supplied from an Indian power plant are IC which is one kind of low-rank coal with high ash content and INC which is always used for the cocombustion with IC for supporting the combustibility in practice.

The MSWH used in this study was obtained from a local city in Hokkaido, Japan. The MSW excluding food residue was treated in a batch scale HT treatment as shown in Figure 1. The HT treatment was operated at $200^{\circ} \mathrm{C}$, $20 \mathrm{~atm}$ with the holding time of 30 minutes using saturated steam. The HT treatment can convert MSW with high moisture content, irregular shapes, and low bulk density into homogeneous solid powder product.

The fuel analysis of the samples such as proximate and ultimate analysis as well as higher heating value (HHV) is listed in Table 1.

All the samples were crushed and milled to the size in the range of $100-180 \mu \mathrm{m}$ in order to avoid the effect of the size distribution. The blends of $80 \%$ IC: $20 \% \mathrm{MSWH}$ and $90 \%$ IC : $10 \%$ INC (wt \%) were prepared by blending individual samples together. Due to the limitation of the screw feeder, quartz sand which is inert in characteristics was added into all the samples at the ratio of sample : quartz sand $=1: 3$ (wt $\%$ ) in order to alleviate the adhesiveness of pure samples ensuring continuous feeding. Before tests, all the samples
TABLe 1: Fuel analysis.

(a) Ultimate analysis ${ }^{\mathrm{a}}$

\begin{tabular}{lccccc}
\hline & $\mathrm{C}(\%)$ & $\mathrm{H}(\%)$ & $\mathrm{N}(\%)$ & $\mathrm{S}(\%)$ & $\mathrm{O}(\%)$ \\
\hline IC & 44.50 & 3.33 & 1.02 & 0.26 & 5.55 \\
MSWH & 45.16 & 6.26 & 0.95 & 0.15 & 24.88 \\
INC & 75.47 & 5.37 & 1.10 & 0.09 & 16.40 \\
B1 $^{\mathrm{b}}$ & 44.63 & 3.92 & 1.01 & 0.24 & 9.42 \\
B2 $^{\mathrm{b}}$ & 47.60 & 3.53 & 1.03 & 0.24 & 6.64 \\
\hline
\end{tabular}

(b) Proximate analysis ${ }^{\mathrm{a}}$ and $\mathrm{HHV}^{\mathrm{a}}$

\begin{tabular}{lcccc}
\hline & $\begin{array}{c}\text { Volatile matter } \\
(\%)\end{array}$ & $\begin{array}{c}\text { Fixed carbon } \\
(\%)\end{array}$ & $\begin{array}{c}\text { Ash } \\
(\%)\end{array}$ & $\begin{array}{c}\text { HHV } \\
(\mathrm{MJ} / \mathrm{kg})\end{array}$ \\
\hline IC & 25.40 & 29.00 & 45.60 & 17.88 \\
MSWH & 70.94 & 6.31 & 22.75 & 17.84 \\
INC & 50.16 & 48.18 & 1.66 & 30.03 \\
B1 $^{\text {b }}$ & 34.51 & 24.46 & 41.03 & 17.87 \\
B2 $^{\text {b }}$ & 27.88 & 30.92 & 41.21 & 19.10 \\
\hline
\end{tabular}

${ }^{a}$ Dry basis (without blending quartz sand).

${ }^{\mathrm{b}}$ Calculated values from the weight ratio.

were dried in an oven for 2 hours because samples with small size have strong tendency to absorb moisture from the air.

For simplification, here $\mathrm{B} 1$ and $\mathrm{B} 2$ refer to the blends of $80 \%$ IC $+20 \%$ MSWH and the blends of $90 \%$ IC $+10 \%$ INC, respectively.

2.2. Drop Tube Reactor System. The laboratory-scale DTR is made of quartz tubing (GE type 214, National Scientific Company) and is $1.8 \mathrm{~m}$ long, $25.4 \mathrm{~mm}$ OD, and $19 \mathrm{~mm}$ ID. The furnace used is a split-hinged vertical furnace with 5 temperature zones (SV Furnace MA no. 100087, Mellen Inc.). The overall experimental scheme is illustrated in Figure 2.

The samples were fed continuously to the DTR using a solid screw feeder. Air was supplied through an air cylinder and the flow rate was maintained by using a mass flow controller (MFC). During the experiments, the flow rate of the exhaust gas could be controlled through a set of a flow meter and a vacuum pump. The compositions of the gas $\left(\mathrm{CO}, \mathrm{CO}_{2}, \mathrm{O}_{2}, \mathrm{NO}, \mathrm{SO}_{2}\right)$ were continuously measured 


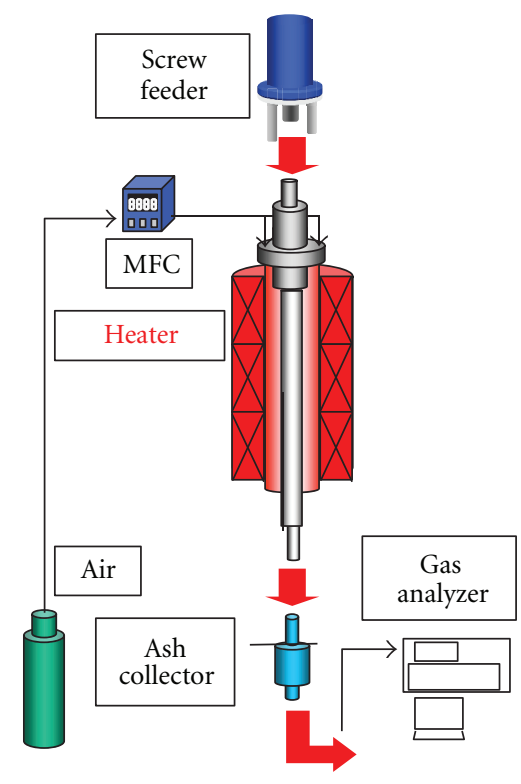

FIgure 2: Schematic diagram of the DTR.

after the system gained its stability by a flow gas analyzer (Integrated Emissions System Model 700, ENERAC, Inc.) and a micro-GC (Quad Series Micro GC, Agilent, Inc.). After each trial, ash was collected through an ash collector for further analysis.

2.3. Testing Matrix. Table 2 shows the experimental matrix. Both the individual samples (IC, MSWH, Inc.) and the blended samples (B1, B2) were tested at 800, 900, 1000, and $1100^{\circ} \mathrm{C}$ at determined excess air $(\varphi)$ of 1.9 to investigate the influence of the temperature on combustion behaviors. Besides that, B1 was selected for a series of further experiments: 5 different $\varphi$ from $1.3 \sim 2.5$ were chosen at $900^{\circ} \mathrm{C}$ to find out the optimal parameter for the combustion of B1. In addition to that, $0.1 \mathrm{~g} / \mathrm{min}$ water which accounts for $20 \%$ of the total feeding amount was injected into the DTR along with $\mathrm{B} 1$ at $900^{\circ} \mathrm{C}(\varphi=1.9)$. The reason for performing this trial was to simulate the combustion practice in the real application which handles with coal/blends of coal and biomass. The moisture contents of the fuels used are normally around or higher than $20 \%$ which may exert positive or negative effects on the combustion characteristics and emissions $[8,9]$ especially when MSWH is introduced into the combustion system.

\section{Results and Discussion}

3.1. Combustion Efficiencies of all the Samples as a Function of Temperature. The combustion efficiency as a function of temperature at $\varphi=1.9$ is depicted in Figure 3. The combustion efficiency $(\eta)$ is defined as follows: $\eta(\%)=$ $(\mathrm{B}-\mathrm{C}) / \mathrm{B} * 100$, where $\mathrm{B}$ and $\mathrm{C}$ stand for the mass fractions of combustible in the feed stock and combustible in the ash collected. From Figure 3(a), it can be found that the $\eta$ of IC, MSWH, and INC showed increasing trends as
TABle 2: Experimental matrix.

(a) IC, MSWH, INC, B1, B2

\begin{tabular}{lc}
\hline Temperature $\left({ }^{\circ} \mathrm{C}\right)$ & $\varphi$ \\
\hline 800 & 1.9 \\
900 & 1.9 \\
1000 & 1.9 \\
1100 & 1.9 \\
\hline
\end{tabular}

(b) B1

\begin{tabular}{lc}
\hline Temperature $\left({ }^{\circ} \mathrm{C}\right)$ & Excess air \\
\hline 900 & 1.3 \\
900 & 1.6 \\
900 & 1.9 \\
900 & 2.2 \\
900 & 2.5 \\
$900\left(+0.1 \mathrm{~g} / \mathrm{min}_{2} \mathrm{O}\right)$ & 1.9 \\
\hline
\end{tabular}

the temperature increased and even linear tendencies could be found from 900 to $1100^{\circ} \mathrm{C}$ for all the three samples $\left(R^{2}>0.98\right.$, where $R^{2}$ is a symbol for the coefficient of determination of a linear regression) which indicated that, at higher temperatures $\left(900 \sim 1100^{\circ} \mathrm{C}\right)$, the combustion was controlled by the temperature and the combustion efficiency of three individual samples could be reasonably predicted. On the other hand, at lower temperature $\left(800^{\circ} \mathrm{C}\right)$, not only the temperature but also the other factors such as oxygen diffusion might also come to play important roles on the combustion especially in the case of INC whose $\eta$ at $800^{\circ} \mathrm{C}$ was extremely low compared to the others indicating that the high content of volatile matter (VM) of INC might discourage the diffusion of air which prohibits the oxygen from reaching the fixed carbon (FC). Although MSWH contained much more VM than INC, its $\eta$ at $800^{\circ} \mathrm{C}$ was still well controlled by the temperature because the burning of VM was mainly responsible for the combustion of MSWH whereas on the other hand in the case of coal, the combustion of FC dominated. Moreover, MSWH presented higher combustion efficiency due to the high amount of VM.

From Figure 3(b), the effects of blending MSWH and INC on the cocombustion characteristics can be observed. The additions of MSWH and INC with higher VM supported the combustion of IC significantly. The $\eta$ of B1 and B2 were elevated by $6.66 \sim 9.28 \%$ and $5.87 \sim 10.71 \%$ respectively when compared to individual IC (see Table $\left.3, \eta_{\mathrm{B} 1(\mathrm{~B} 2)}-\eta_{\mathrm{IC}}\right)$. The lower the temperature was, the higher the effectiveness of the blending would be. This implied that at lower temperature the blending of MSWH and INC with higher VM contents (Table 1) promoted combustion more significantly. The release of more VM from MSWH and INC at higher temperature might partially reduce the concentration of oxygen near the char particles and prevented the oxygen from contacting with char leading to the drop of $\eta$ enhancement at higher temperatures. Moreover, similar to individual samples, the improvements of $\eta$ by increasing the temperature from $900^{\circ} \mathrm{C}$ to $1100^{\circ} \mathrm{C}$ for the two blends were also linear $\left(R^{2}>\right.$ 0.92). Furthermore, from Table 3 the experimental values of 


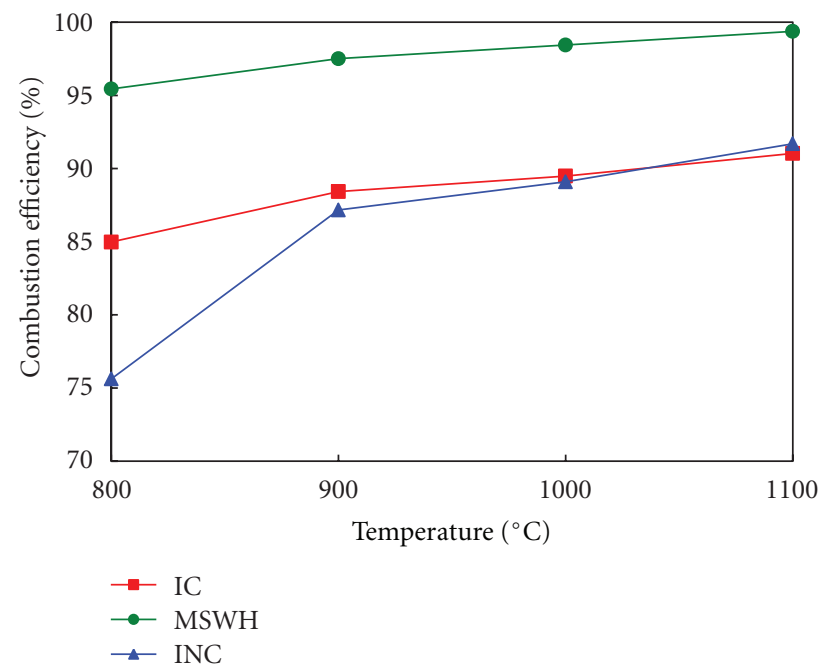

(a)

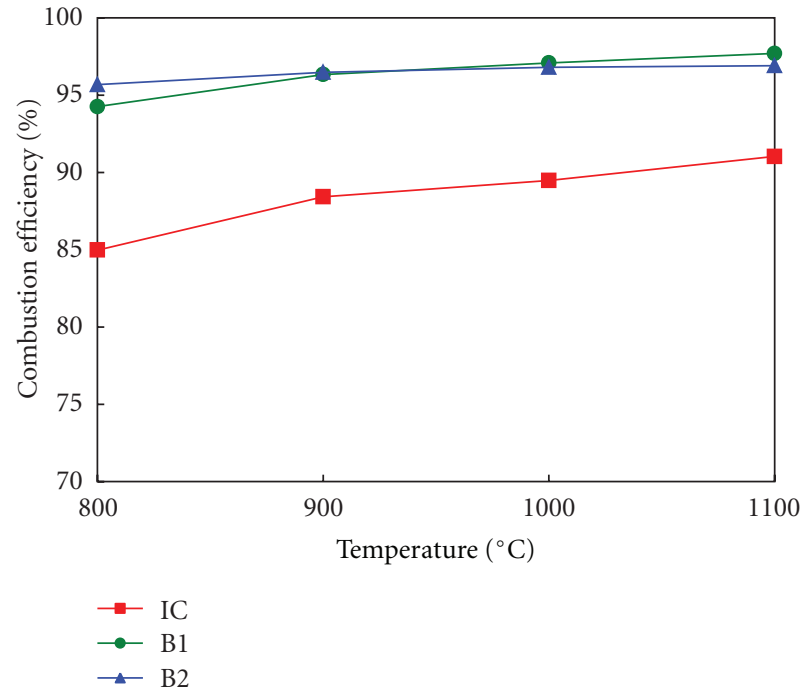

(b)

Figure 3: Combustion efficiency as a function of temperature $(\varphi=1.9)$.

$\eta$ were always higher than those of the calculated ones which suggested that there should be some interaction between the additives and IC. It was also supported by the TGA experiment in our previous work that at lower blending ratio of MSWH, there was some synergic relationship between MSWH and IC [3].

\subsection{Emissions of All the Samples as a Function of Temperature}

3.2.1. CO Emission. The emission of CO of all the samples as a function of temperature at $\varphi=1.9$ is shown in Figure 4 . For individual samples (Figure 4(a)), MSWH and INC shared the same trend that the $\mathrm{CO}$ emission fell with temperature which was because that the $\mathrm{CO}$ oxidation to $\mathrm{CO}_{2}$ was favored at higher temperature. However, from $800^{\circ} \mathrm{C}$ to $900^{\circ} \mathrm{C}$, IC showed a significant increase in $\mathrm{CO}$ emission and the reason might be ascribed to the low combustibility of IC char which is surrounded by huge amount of ash $(45.60 \%$ ash for IC, Table 1) implying that the whole combustion efficiency would be low for IC at low temperature $\left(800^{\circ} \mathrm{C}\right)$ although the $\mathrm{CO}$ emission at this temperature is lower. When comparing the three individual samples in Figure 4(a), it is obvious that MSWH emitted least CO followed by INC and IC. As a well-known fact, VM which is in gaseous state during the devolatilization gets ignited and burned more easily than FC or char. So it is reasonable that MSWH which was rich in VM showed the lowest $\mathrm{CO}$ emission.

When it comes to the blends (Figure 4(b)), although the blends showed the similar trends of CO emission evolution as a function of temperature as IC, it seemed that the blendings of both MSWH and INC contributed to the reduction of $\mathrm{CO}$ emission of IC significantly. From Table 3 , it is obvious that the experimental values of $\mathrm{CO}$ emission at all the temperature for both B1 and B2 were much lower than those of calculated values which again demonstrated that there was certain interactive reaction between MSWH (INC) and IC.
3.2.2. NO Emission. Because the temperature of this study was no higher than $1100^{\circ} \mathrm{C}$, fuel-NO formation was considered to be the most predominant one while thermal-NO and prompt-NO could be neglected. The emission of NO of all the samples as a function of temperature at the excess air of 1.9 is shown in Figure 5. From Figure 5(a), MSWH emitted more NO than the coals although the nitrogen content of MSWH was the lowest (Table 1). It can be ascribed to that the main nitrogen compounds of MSW components (paper especially) were simple proteins known to release $\mathrm{NH}_{3}$, which was easily oxidized to form $\mathrm{NO}$ whereas the nitrogen compounds of coals were essentially contained in aromatic heterocycles which were hard to be released and converted into NO [10]. Normally, the higher the rank of coal was (here INC > IC), the more nitrogen compounds were constrained in the aromatic heterocycles which gave an explanation of the lower NO concentration of INC than that of IC. For the effect of temperature on the NO emissions of the three individual samples in Figure 5(a), at $800^{\circ} \mathrm{C}$, the NO concentrations of the three samples were the lowest which was possibly due to (1) the low temperature leading to the abatement of emissions of nitrogen compounds in the case of IC and INC; (2) the high CO concentration at $800^{\circ} \mathrm{C}$ in the case of $\mathrm{MSWH}$ and $\mathrm{INC}$ resulting in the acceleration of $\mathrm{NO}$ destruction on the surface of char [10, 11]. At $900^{\circ} \mathrm{C}$, the $\mathrm{NO}$ concentrations of IC and MSWH rose greatly because the formation of $\mathrm{NO}$ was favored at higher temperature whereas the NO emission only increased slightly for INC in which case a significant $\mathrm{NO}$ emission could be observed at $1000^{\circ} \mathrm{C}$ indicating that, for high-rank coal as INC, the release of nitrogen compounds from aromatic heterocycles required more energy. At $1000^{\circ} \mathrm{C}$, $\mathrm{NO}$ emission of IC only increased a little bit compared to the case at $900^{\circ} \mathrm{C}$ implying that the nitrogen compounds of IC were almost emitted at $900^{\circ} \mathrm{C}$. For MSWH, since the rate of VM release became higher at higher temperature $\left(1000-1100^{\circ} \mathrm{C}\right)$, 
TABle 3: Comparison of $\eta, \mathrm{CO}$, and $\mathrm{NO}$ emissions between experimental value and calculated value and the enhancement of the $\eta$ by blending.

\begin{tabular}{lcccc}
\hline$T\left({ }^{\circ} \mathrm{C}\right)$ & $\eta(\%)$ & $\eta_{\mathrm{B} 1(\mathrm{~B} 2)}-\eta_{\mathrm{IC}}(\%)$ & CO $(\mathrm{ppm})$ & $\mathrm{NO}(\mathrm{ppm})$ \\
\hline $\mathrm{B} 1$ & $\mathrm{a}(\mathrm{b})$ & $\mathrm{a}$ & $1954(3352)$ & $\mathrm{a}(\mathrm{b})$ \\
\hline 800 & $94.26(87.07)$ & 9.28 & $2363(4042)$ & $281(240)$ \\
900 & $96.34(90.25)$ & 7.91 & $2333(3646)$ & $370(342)$ \\
1000 & $97.08(91.28)$ & 7.60 & $2305(2963)$ & $439(339)$ \\
1100 & $97.70(92.71)$ & 6.66 & $\mathrm{a}(\mathrm{b})$ & $438(324)$ \\
\hline $\mathrm{B} 2$ & $\mathrm{a}(\mathrm{b})$ & $\mathrm{a}$ & $3146(3372)$ & $\mathrm{a}(\mathrm{b})$ \\
\hline 800 & $95.69(84.04)$ & 8.05 & $2243(226)$ & $252(3853)$ \\
900 & $96.48(88.30)$ & 7.32 & $2038(3091)$ & $384(333)$ \\
1000 & $96.81(89.45)$ & 5.87 & & $435(313)$ \\
\hline
\end{tabular}

axperimental value obtained from the measured data.

${ }^{b}$ Calculated value obtained on the assumption of the compositional ratio of the blends.

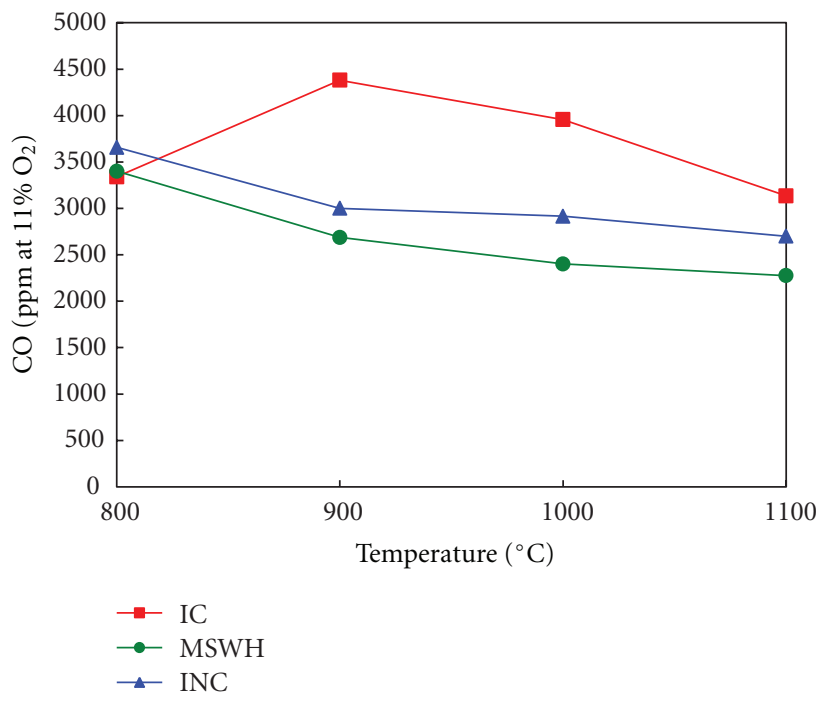

(a)

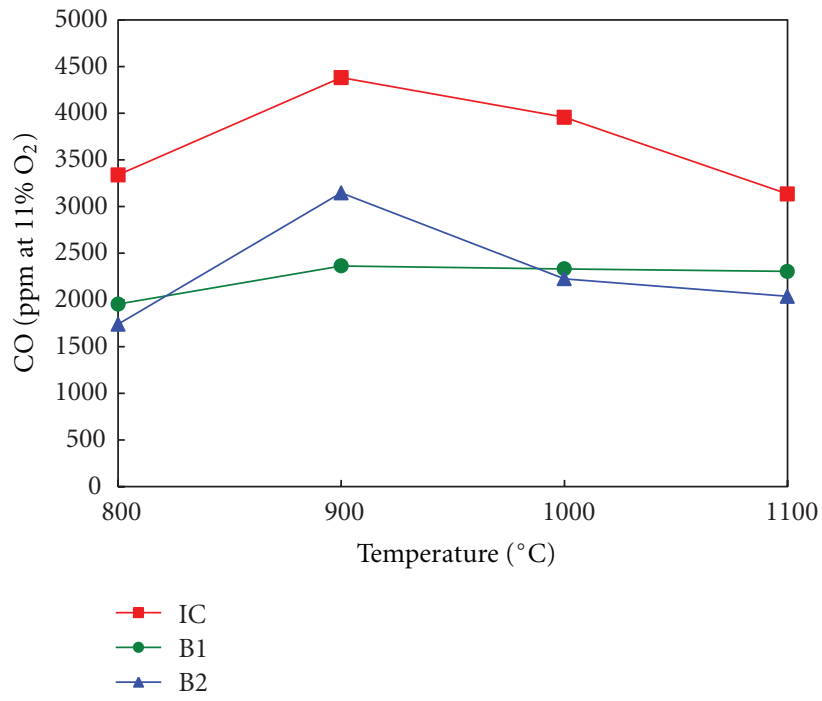

(b)

FIGURE 4: CO emissions as a function of temperature $(\varphi=1.9)$.

the reducing environment and more available hydrocarbon radicals contributed to the destruction of $\mathrm{NO}$ and so were the cases of IC and INC at $1100^{\circ} \mathrm{C}$.

In the cases of the blends burning (Figure 5(b)), for B1, at all the four temperatures, the NO emissions were higher than that of IC only. The NO emission of B1 kept rising until $1000^{\circ} \mathrm{C}$ which was not similar to the case of IC and MSWH only. Because the $\mathrm{CO}$ concentration of $\mathrm{B} 1$ was much lower than that of IC (Figure 4(b)), the NO destruction through the catalyzing reaction on the char surface with $\mathrm{CO}$ was also restricted. Additionally, it is concluded that the addition of high VM containing biomass such as chicken litter at low concentrations resulted in higher $\mathrm{NO}$ emissions because more fuel- $\mathrm{N}$ was introduced whereas blending at high ratios might reduce NO emissions due to the larger amount of released $\mathrm{VM}$, which suppressed the formation of $\mathrm{NO}[12]$. When it comes to $\mathrm{B} 2$, the trend of $\mathrm{NO}$ evolution from $800 \sim 1000^{\circ} \mathrm{C}$ seemed similar to that of INC only although the values became higher which could be attributed to the same reason as in the case of B1. $10 \%$ of INC in B2 took over the $\mathrm{NO}$ emission or in other words dominated the reaction of NO formation and destruction. It is assumed that the VM of INC of low reactivity which might not be completely consumed at lower temperature prohibited the oxygen from contacting with the IC particles resulting in retention of the nitrogen compounds in IC. On the other hand, the VM helped the reduction of NO as well due to available hydrocarbon radicals. Moreover, from Figure 4(b), the CO concentration of B2 at $900^{\circ} \mathrm{C}$ was extremely high when compared with the cases at other temperatures because unburned VM might constitute an additional $\mathrm{CO}$ source. From Table 3, the experimental values of $\mathrm{NO}$ emission at all the temperature for both $\mathrm{B} 1$ and $\mathrm{B} 2$ were higher than those of calculated values. The lower $\mathrm{CO}$ and some kind of synergic behaviors might be responsible for that. 


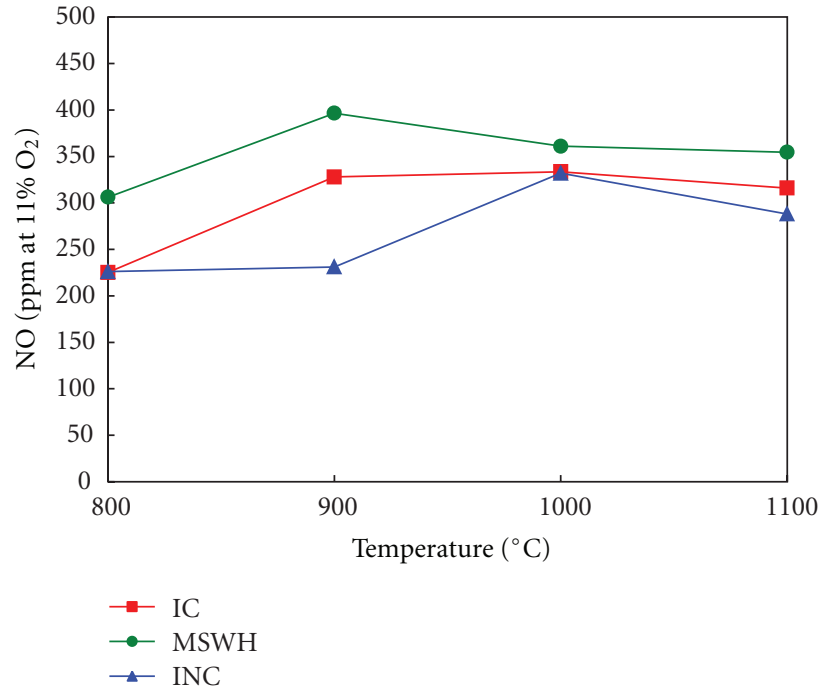

(a)

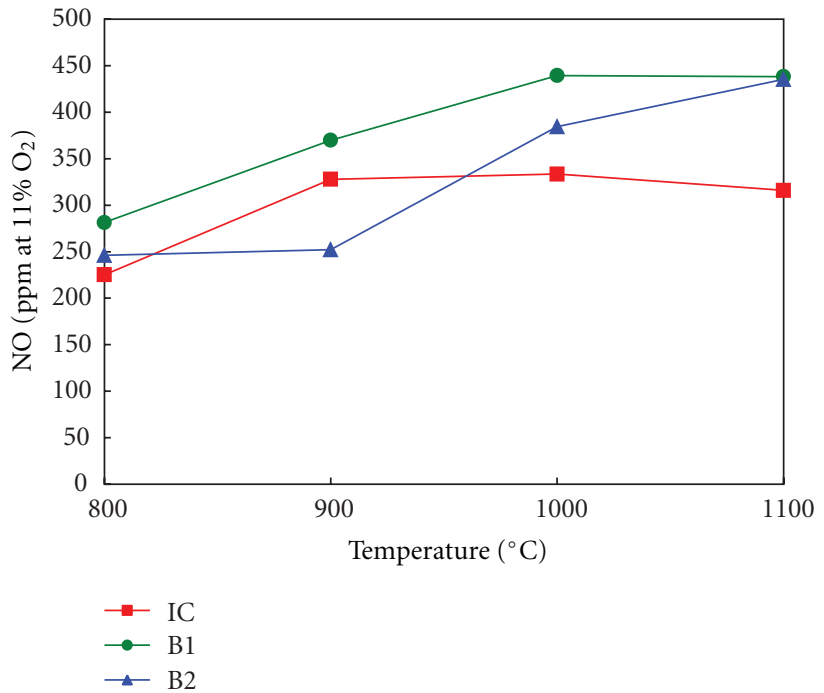

(b)

Figure 5: NO emissions as a function of temperature $(\varphi=1.9)$.

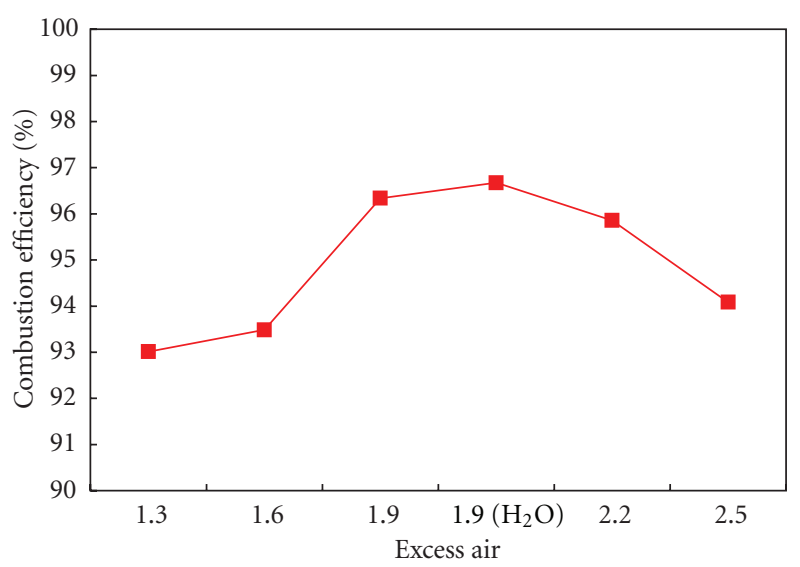

(a)

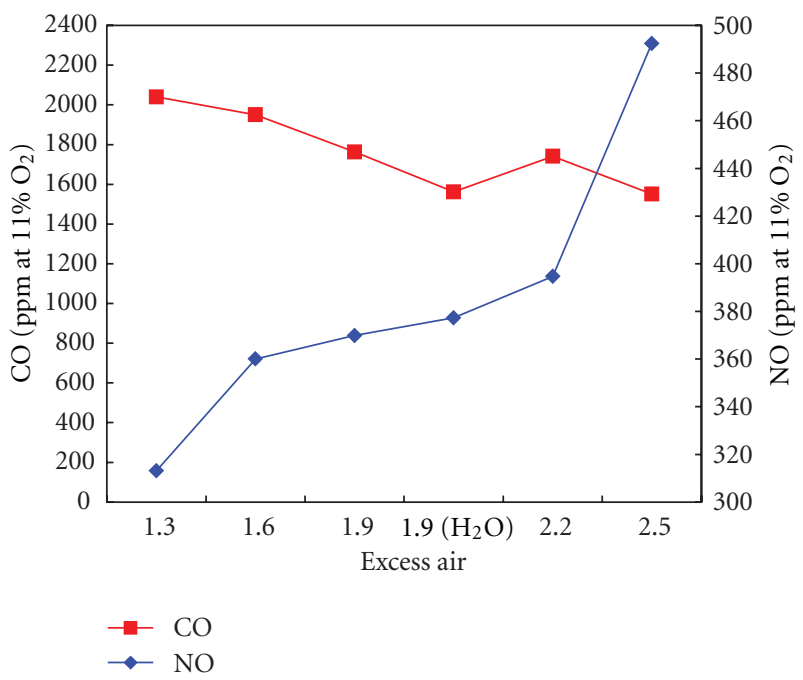

(b)

FIGURE 6: Combustion behaviors of $\mathrm{B} 1$ at different conditions (at $900^{\circ} \mathrm{C}$ ).

3.3. Effects of Excess Air and Moisture on the Cocombustion Behavior of MSWH with IC. Figure 6 shows the combustion efficiency and $\mathrm{CO}, \mathrm{NO}$ emissions of $\mathrm{B} 1$ as a function of the excess air at $900^{\circ} \mathrm{C}$. From Figure $6(\mathrm{a})$, it is obvious that the highest $\eta$ was obtained at $\varphi=1.9$ especially when there was water in the combustion system at which condition $\eta$ reached $96.7 \%$. It is also clear that the higher the excess air was, the higher the $\eta$ would be when $\varphi$ was below 1.9. The oxidations of $\mathrm{CO}$ and hydrocarbons were favored at high oxygen concentration. However, when $\varphi$ exceeded $1.9, \eta$ decreased with $\varphi$ increasing. This was because that the temperature in the tube furnace would be inevitably decreased to some extent with the increase of $\varphi$ due to more cool air to be heated up [11]. The decrease in furnace temperature thus led to the drop of $\eta$. Although many researchers concluded that the moisture content in the MSW led to low combustion efficiency [13], the small amount of water injection $(0.1 \mathrm{~g} / \mathrm{min})$ in this study helped to improve $\eta$ slightly compared with the case without water injection. The reason might be that the existence of water molecule at high temperature contributes to the increase of $\mathrm{H}$ and $\mathrm{OH}$ radicals which could be reacted with $\mathrm{CO}$ thus promoting the conversion of FC to $\mathrm{CO}$ or $\mathrm{CO}_{2}$.

The $\mathrm{CO}$ and $\mathrm{NO}$ evolution of $\mathrm{B} 1$ as a function of the excess air is depicted in Figure 6(b). CO fell with the increase of $\varphi$ whereas on the other hand NO displayed an opposite tendency. The lower $\mathrm{CO}$ emission at higher $\varphi$ was due to the enhancement in available oxygen which led to 
the acceleration of $\mathrm{CO}$ oxidation. On the other hand, lower $\mathrm{CO}$ at higher $\varphi$ resulted in the attenuation of reduction environment thus slowing down the reaction between $\mathrm{CO}$ and NO on char surfaces. Meanwhile, the higher oxygen content at higher $\varphi$ promoted the conversion of nitrogen compounds to NO. As mentioned above, moisture injection facilitated the formation of $\mathrm{CO}_{2}$ through $\mathrm{H}$ and $\mathrm{OH}$ reacting with $\mathrm{CO}$. On the other hand, $\mathrm{O}$ and $\mathrm{OH}$ radicals of high reactivity also reacted easily with $\mathrm{NH}_{3}$ species to form NO [6].

At $900^{\circ} \mathrm{C}$, the most optimal condition for B1 combustion was assumed to be at $\varphi=1.9$. Small quantity of water injection (equaling to $20 \%$ moisture) into the combustion system led to the improvement of the combustion efficiency, the reduction of $\mathrm{CO}$ emission, and increase of NO. The results further permitted the direct utilization of naturally dried MSWH for cocombustion with coal.

\section{Conclusions}

The introduction of the MSWH into the cocombustion system supporting the utilization of low-rank coal not only provides a good treatment for MSW but also cuts the usage of solid energy resource of high-rank coal. The results obtained in this research can be summarized as follows.

(1) The combustion efficiency of IC was elevated by blending both MSWH and INC and CO emission was reduced by increasing the temperature.

(2) With regards to NO emission, the blending of MSWH led to the increase of $\mathrm{NO}$ emission whereas the blending of INC resulted in either increase or decrease of $\mathrm{NO}$ emission compared with IC only depending on the temperature.

(3) The combustion efficiency and CO and NO emissions of IC-MSWH blend were comparable to those of IC-INC blend especially at higher temperature indicating it is viable to replace INC with HT-treated MSW in cocombustion with IC.

(4) At the excess air of 1.9, the combustion efficiency of IC-MSWH blend showed the highest value. The $\mathrm{CO}$ emission fell and the $\mathrm{NO}$ emission rose with the increase of the excess air in the case of IC-MSWH blend at $900^{\circ} \mathrm{C}$.

(5) $20 \%$ moisture content of the IC-MSWH blends could improve the combustion efficiency, reduce $\mathrm{CO}$ emission, and increase $\mathrm{NO}$ emission. It is possible to directly utilize the hydrothermally treated MSW for the cocombustion with IC.

\section{References}

[1] M. Muthuraman, T. Namioka, and K. Yoshikawa, "A comparative study on co-combustion performance of municipal solid waste and Indonesian coal with high ash Indian coal: a thermogravimetric analysis," Fuel Processing Technology, vol. 91, no. 5, pp. 550-558, 2010.
[2] M. Goto, R. Obuchi, T. Hirose, T. Sakaki, and M. Shibata, "Hydrothermal conversion of municipal organic waste into resources," Bioresource Technology, vol. 93, no. 3, pp. 279-284, 2004.

[3] M. Muthuraman, T. Namioka, and K. Yoshikawa, "Characteristics of co-combustion and kinetic study on hydrothermally treated municipal solid waste with different rank coals: a thermogravimetric analysis," Applied Energy, vol. 87, no. 1, pp. 141-148, 2010.

[4] M. Muthuraman, T. Namioka, and K. Yoshikawa, "A comparison of co-combustion characteristics of coal with wood and hydrothermally treated municipal solid waste," Bioresource Technology, vol. 101, no. 7, pp. 2477-2482, 2010.

[5] S. Jomaa, A. Shanableh, W. Khalil, and B. Trebilco, "Hydrothermal decomposition and oxidation of the organic component of municipal and industrial waste products," Advances in Environmental Research, vol. 7, no. 3, pp. 647-653, 2003.

[6] S. Biswas, N. Choudhury, P. Sarkar et al., "Studies on the combustion behaviour of blends of Indian coals by TGA and Drop Tube Furnace," Fuel Processing Technology, vol. 87, no. 3, pp. 191-199, 2006.

[7] K. Le Manquais, C. Snape, I. McRobbie, J. Barker, and V. Pellegrin, "Comparison of the combustion reactivity of TGA and drop tube furnace chars from a bituminous coal," Energy and Fuels, vol. 23, no. 9, pp. 4269-4277, 2009.

[8] K. Suksankraisorn, S. Patumsawad, and B. Fungtammasan, "Co-firing of Thai lignite and municipal solid waste (MSW) in a fluidised bed: Effect of MSW moisture content," Applied Thermal Engineering, vol. 30, no. 17-18, pp. 2693-2697, 2010.

[9] H. Tsuji, H. Shirai, H. Matsuda, and P. Rajoo, "Emission characteristics of NOx and unburned carbon in fly ash on high-ash coal combustion," Fuel, vol. 90, no. 2, pp. 850-853, 2011.

[10] E. Desroches-Ducarne, E. Marty, G. Martin, and L. Delfosse, "Co-combustion of coal and municipal solid waste in a circulating fluidized bed," Fuel, vol. 77, no. 12, pp. 1311-1315, 1998.

[11] K. Suksankraisorn, S. Patumsawad, P. Vallikul, B. Fungtammasan, and A. Accary, "Co-combustion of municipal solid waste and Thai lignite in a fluidized bed," Energy Conversion and Management, vol. 45, no. 6, pp. 947-962, 2004.

[12] S. G. Li, A. Wu, S. Deng, and W. P. Pan, "Effect of cocombustion of chicken litter and coal on emissions in a laboratory-scale fluidized bed combustor," Fuel Processing Technology, vol. 89, no. 1, pp. 7-12, 2008.

[13] M. Ikeda, H. Makino, H. Morinaga, K. Higashiyama, and Y. Kozai, "Emission characteristics of NOx and unburned carbon in fly ash during combustion of blends of bituminous/subbituminous coals," Fuel, vol. 82, no. 15-17, pp. 1851-1857, 2003. 

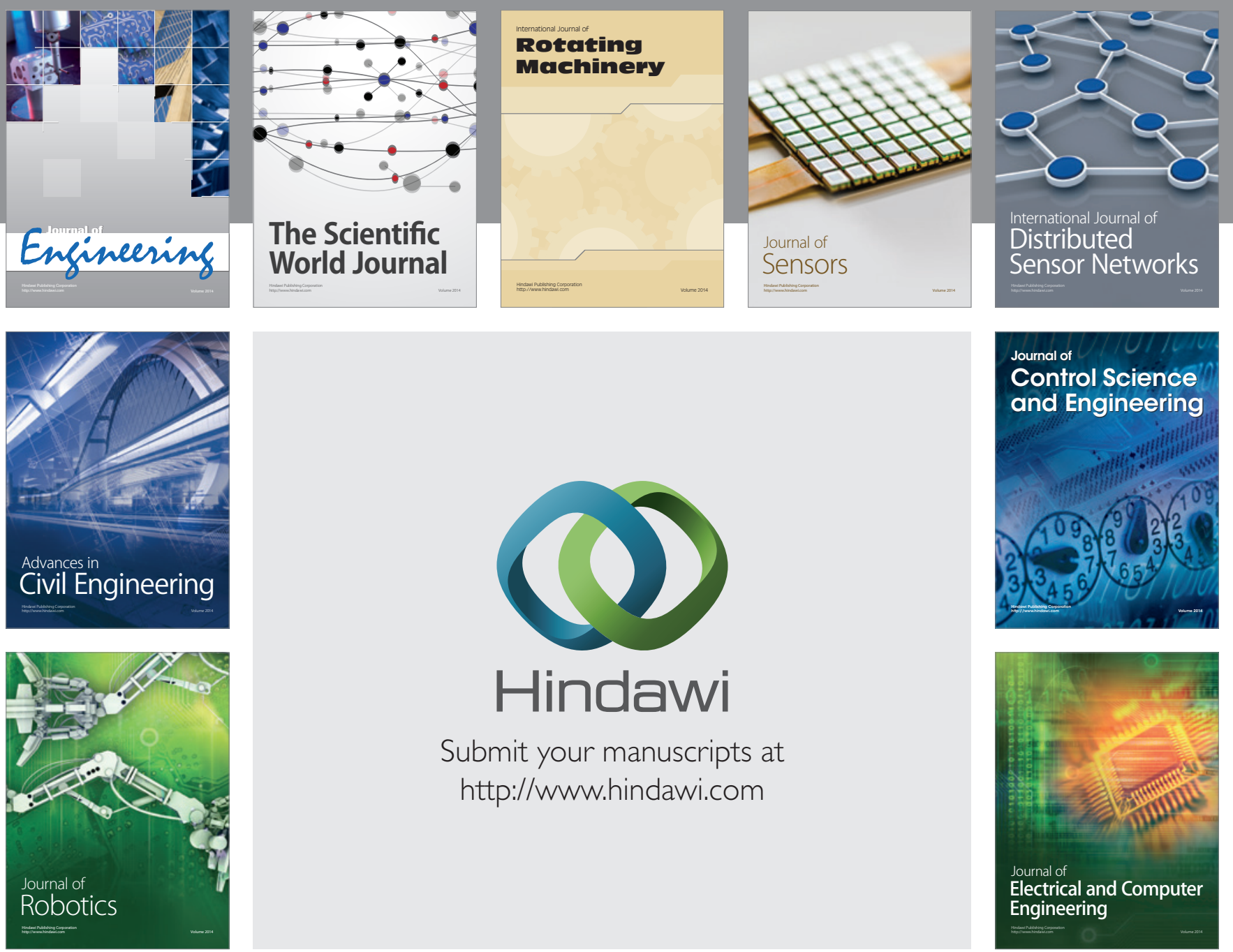

Submit your manuscripts at

http://www.hindawi.com
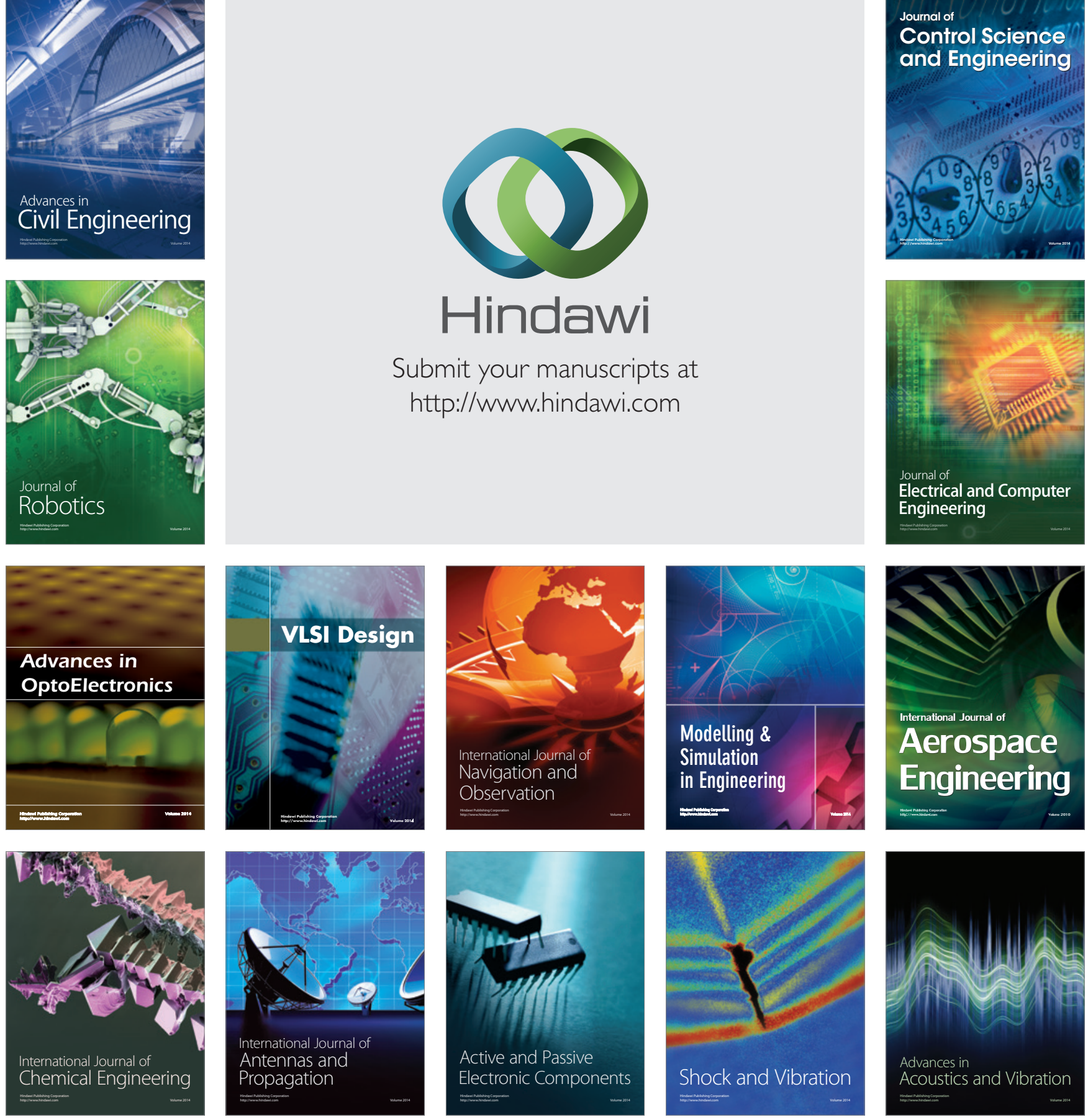